\title{
Influence of slope of grain on the mechanical properties of tropical hardwoods and the consequences for grading
}

\author{
Geert Ravenshorst ${ }^{1} \cdot$ Wolfgang Gard ${ }^{1} \cdot$ Jan Willem van de Kuilen ${ }^{1,2}$
}

Received: 18 November 2019 / Published online: 19 August 2020

(c) The Author(s) 2020

\begin{abstract}
The main parameter that influences the bending strength of timber from tropical hardwood is the slope of grain. Although, in the grading rules, a specific threshold value is given, in these hardwoods, the global slope of grain is very difficult to quantify by visual assessment. The slope of grain measured after testing gives a better indication, but still it can only poorly describe the Hankinson relations. By rewriting the Hankinson relations, the slope of grain can be determined from the bending strength test values and from the MOE test value, both in combination with the density values and constants derived by non-linear regression analysis. These two values correlate very well, and the average value is designated as the theoretical slope of grain. With the theoretical slope of grain, five test samples of the tropical wood species okan were evaluated, and slope of grain values of 0.3 were observed, where 0.1 is the limit value. Because all pieces passed the visual grading method as applied in practice, slope of grain values should be incorporated in the strength class assignment test program, when these qualities cannot be ruled out for coming on the market. The (dynamic) modulus of elasticity can be used to evaluate the occurrence of the desired range of slope of grain values in the test samples.
\end{abstract}

\section{Introduction}

To assign a timber beam to a strength class, this beam has to be graded. With visual grading, the grader assesses the most important strength reducing characteristics and designates the visual grade of the beam. In a previously performed laboratory research, the relationship between the visual characteristics and the strength was determined and based on that the strength class connected to that specific visual grade was established. This is documented in grading reports and for a number of species, there is a European standard (EN 1912 2012) that provides information on strength classes that can be assigned to visual grades of a number of species from different growth areas. In Europe, there is a harmonised standard (EN 14081-1 2016) that provides guidance how strength assignments should be performed, to ensure that the same method is followed all over Europe. The harmonised standard is referring to the standard EN 384 (2016)

Geert Ravenshorst

g.j.p.ravenshorst@tudelft.nl

1 Faculty of Civil Engineering and Geosciences, Delft University of Technology, Delft, The Netherlands

2 Holzforschung München, TU München, Munich, Germany that gives guidelines for sampling in connection with visual grading. This paper discusses the influence of the strength reducing characteristic slope of grain in combination with visual grading.

EN 384 states how the characteristic value of, for instance, the bending strength can be determined based on the number of samples and specimens within a sample for a visual grade, which means that prior to the laboratory testing, the material has to be subdivided into visual grades defined in visual grading standards. For softwoods, the knot ratio (the size of the knots related to the size of the beam) is the most governing strength reducing parameter. It is possible to distinguish between different values of knot ratios during grading in practice. Therefore, it is possible to divide softwood into 2 or 3 visual grades. For tropical hardwoods, however, the slope of grain (defined as the deviation of the grain angle with the longitudinal beam axis) is the most important strength-reducing characteristic (since in most cases, no knots are present). However, the slope of grain is difficult to determine in the grading process. Ehrhart et al. (2018) explain this for the case of beech. A common way is to evaluate the drying cracks that normally follow the slope of grain. Ehrhart et al. (2018) show the potential for beech to measure the direction of the medullary rays with cameras to predict the slope of grain. Whether a similar approach could 
work for tropical hardwoods should be investigated. Because the value of the slope of grain is more difficult to determine in practice, for tropical hardwoods only one visual grade defined is for a wood species. For instance, there is only one visual grade for tropical hardwoods in the Europeans standard EN 16737 (2016) or in the Dutch standard NEN 5493 (2010). For these visual grades, the slope of grain is limited to a value of 1:10. Beams with higher slope of grain should be rejected. Figure 1 shows the definition of slope of grain according to EN 1310 (2012). The slope of grain is the tangent of the angle of the grain to the beam axis; sometimes multiplied by 100 to express it as a percentage. In this paper, slope of grain $(\mathrm{SoG})$ is given as the tangent of the angle of the grain to the beam axis (x/y in Fig. 1). This paper focusses on tropical hardwoods, where the slope of grain in most cases is the only strength-reducing parameter, as no knots are present. The problem of measuring the slope of grain is however also present for European hardwoods like beech as described, for example, in Cibecchini et al. (2016), where a mixture of pieces with large knots and pieces with small knots and significant slope of grain can occur.

However, related to the requirements for visual grading of tropical hardwoods for slope of grain, there are two assumptions that are important in this process. The visual grading for the slope of grain is assumed to be correctly performed in practice and related to that the sampling for the laboratory research, to determine the strength class assignment is representative. These two assumptions will be investigated in this paper.

\section{Influence of the slope of grain on the bending strength and bending stiffness}

The influence of the grain angle on the strength is described in EC 5 (NEN 1995-1-1 2005) by the so-called Hankinson equation. However, in EC 5, it is used for stress verification as the result of a force acting under an angle with the longitudinal beam axis, thereby assuming that the grain direction is parallel to the longitudinal beam axis.

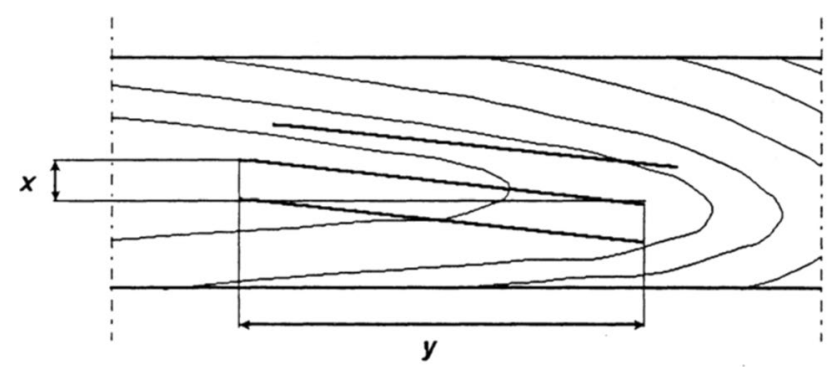

Fig. 1 Definition of slope of grain according to EN 1310
Hankinson (1932) based his equation on compression tests. From a theoretical point of view, the Hankinson equation describes the interaction between stresses parallel and perpendicular to the grain, which has proven to also be valid for tension under an angle with the grain, as well as for bending properties with varying slope of grain. For instance, Pope et al. (2005) concluded that the influence of the slope of grain on the bending strength of scaffold boards from European whitewood was according to Hankinson's equation. Equation (1) gives the Hankinson equation for the bending strength and Eq. (2) for the modulus of elasticity.

$$
\begin{aligned}
& f_{m, \alpha}=\frac{f_{m, 0}}{\left(\frac{f_{m, 0}}{f_{m, 90}}\right) \times \sin ^{2}(\alpha)+\cos ^{2}(\alpha)} \\
& M O E_{\alpha}=\frac{M O E_{0}}{\left(\frac{M O E_{0}}{M O E_{90}}\right) \times \sin ^{2}(\alpha)+\cos ^{2}(\alpha)}
\end{aligned}
$$

Figure 2 shows results of tests performed on specifically prepared specimens of the tropical hardwood species massaranduba with a depth of $50 \mathrm{~mm}$ according to the provisions of EN 408 as described in Ravenshorst (2015). These graphs show that the effect of increasing slope of grain is not linear with the bending strength. Through a non-linear regression analysis, the values for $\mathrm{f}_{\mathrm{m}, 0}$ and $\mathrm{f}_{\mathrm{m}, 90}$ were determined (and also $\mathrm{MOE}_{0}$ and $\mathrm{MOE}_{90}$ ) and inserted into Eqs. (1) and (2). The lines that follow Eqs. (1) and (2) are shown in the figures together with the original data. The graphs show the limit value of 1:10 that is used for the visual grade of tropical hardwood. The left graph in Fig. 2 shows that the reduction in bending strength when the slope of grain increases from $\mathrm{SoG}=0$ to 0.1 is $85 \%$, and when the slope of grain increases from 0 to 0.2 , the reduction in bending strength is $50 \%$, revealing the importance of limiting the slope of grain.

\section{Measuring of slope of grain}

\subsection{Introduction}

The slope of grain is evaluated in the grading process but can also be studied in the laboratory. Figure 3 (left) shows the measurement of the slope of grain on a timber beam determined before testing and after a bending test. On the right, two beams of the tropical hardwood species okan are shown that have to be graded. 

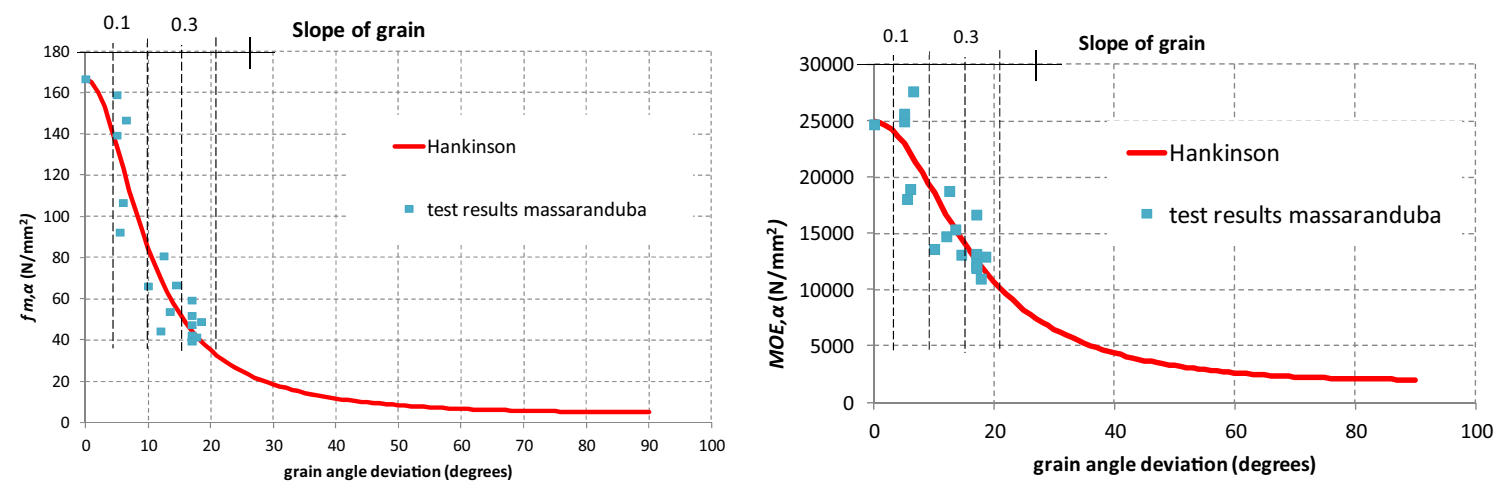

Fig. 2 Influence of slope of grain on bending strength (left) and modulus of elasticity (right) of specimens of massaranduba according to Ravenshorst (2015)
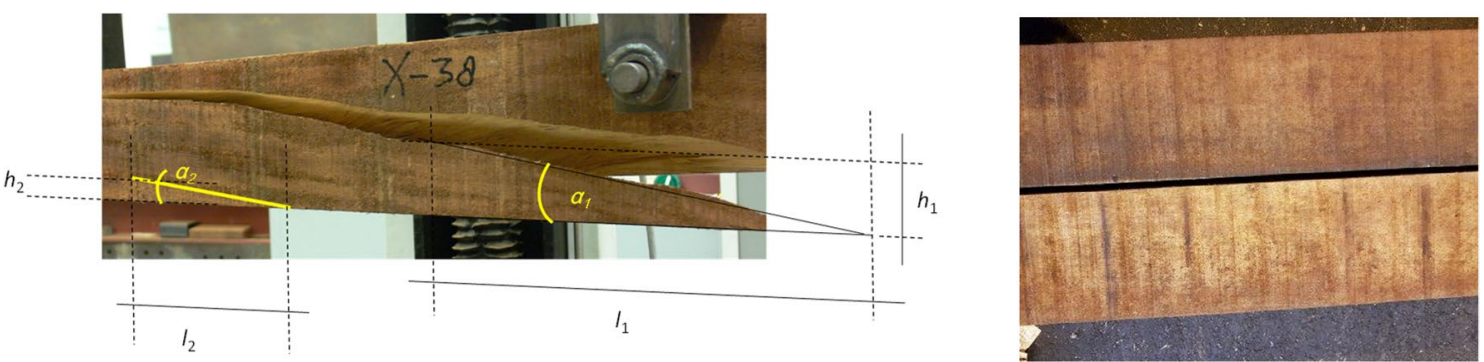

Fig. 3 Angle of the grain and associated slope of grain measured before $\left(\alpha_{2}\right)$ and after $\left(\alpha_{1}\right)$ the bending test (left) and two okan beams that have to be graded (right)

\subsection{Measuring the slope of grain in the grading process}

For tropical hardwoods, there is only one visual class with the requirement that the value for the slope of grain must be limited to $1: 10$, according to the grading standards NEN 5493 (2010) or EN 16737 (2016). In contrast to visual grading on the basis of knots, determining the exact slope of grain in practice is very difficult. Therefore, in practice, graders will not determine the slope of grain exactly before they make the classification of the beam; they will only judge whether the slope of grain is within the required limit. When the slope of grain is assessed to be out of the limits, the beam will be rejected. Figure 3 (right) shows how difficult the determination of the slope of grain in practice can be.

\subsection{Measuring the slope of grain after testing}

After testing in the laboratory, the slope of grain can be measured based on the failure cracks that follow the grain (although this is also sometimes difficult) (see Fig. 3 left). EN 384 (2016) states that in the report for visual grading assignment, histograms showing the distributions of knot size measurements, rate of growth and density of the tested samples should be included. This requirement is clearly focused on softwoods, and in practice, in reports dealing with tropical hardwoods, distributions of the slope of grain are necessary to give insight into the distribution of the strength-reducing characteristics. EN 384 does not state whether these distributions should be measured before or after testing. However, to gain insight into the actual influence it is more valuable to give the slope of grain values after testing. In Ravenshorst (2015), it was shown that when beams from a large number of species are evaluated, the influence of the slope of grain is visible, but with much more scatter than when specimens are specifically prepared as described in Sect. 2.

\subsection{Comparison of slope of grain measurements before and after testing}

To evaluate the predicting capability of the slope of grain after failure on measurements before testing, two samples of hardwood timber species were investigated. All pieces were visually graded as is common practice with the result that the slope of grain was acceptable for all pieces shown and none of them had to be rejected. Then, the slope of 
grain was measured in the laboratory before and after testing according to Fig. 3 (left). Figure 4 (left) shows the results for a sample of okan and Fig. 4 (right) shows the results for a sample of greenheart. Figure 4 shows that it is very difficult to predict the slope of grain after failure with measurements of the slope of grain before testing, that there is a large scatter, and that it also depends on the species or sample. For the okan sample (left), it was much more difficult than for the greenheart sample. The slope of grain often exceeds the maximum value of 0.1 according to the visual grading standards, although once again it has to be mentioned that all pieces passed the normal visual grading process.

\section{Theoretical derivation of the slope of grain}

According to Sect. 2, the slope of grain has an effect on both the bending strength and the modulus of elasticity, which explains why the modulus of elasticity and the bending strength are well correlated. In Ravenshorst (2015), the Hankinson equations were rewritten according to Eqs. (3) and (4).

$$
\begin{aligned}
& f_{m, \alpha}=\frac{\left(\rho C_{1}\right)}{\left(C_{3}-1\right) \sin ^{2}(\alpha)+1} \\
& M O E_{\alpha}=\frac{\left(\rho C_{2}\right)}{\left(C_{4}-1\right) \sin ^{2}(\alpha)+1}
\end{aligned}
$$

where $\rho$ is the density, $\alpha$ the grain angle and $\mathrm{C}_{1}, \mathrm{C}_{2}, \mathrm{C}_{3}$ and $\mathrm{C}_{4}$ are constants. Equations (3) and (4) can be rewritten to Eqs. (5) and (6), respectively, to calculate $\sin ^{2}(\alpha)$ when the actual values of the density, bending strength and MOE are known. $\sin ^{2}(\alpha)=\left[\frac{\left(\rho C_{1}\right)}{f_{m, \alpha}}-1\right] \frac{1}{\left(C_{3}-1\right)}$

$\sin ^{2}(\alpha)=\left[\frac{\left(\rho C_{2}\right)}{M O E_{\alpha}}-1\right] \frac{1}{\left(C_{4}-1\right)}$

For this paper, a dataset of five samples of the timber species okan originating from Africa as described in Ravenshorst and van de Kuilen (2018) was studied. Each sample of okan (Cylicodiscus gabunensis Harms) consisted of approximately 50 pieces with a depth between 100 and $150 \mathrm{~mm}$. All pieces were tested according to EN 408. In some samples, there were a few pieces that were rejected because compression failure was detected. These pieces are not included in the analysis. Figure 5 shows the mean values of the bending strength, dynamic modulus of elasticity and the density at $12 \%$ for all five okan samples. The figures show that the mean values of the bending strength and the dynamic modulus of elasticity are related to each other, but that these two properties do not relate to the density. This can be explained by the fact that varying slope of grain influences the bending strength and modulus of elasticity, but not the density. Ravenshorst (2015) found that for clear wood there is a good correlation of the density with the bending strength and the stiffness. However, for structural sizes, the influence of the slope of grain on the bending strength and stiffness is much stronger. Because there is no correlation between the occurrence of varying slope of grain and the density (which is also not expected from a physical point of view), for structural sizes, a low correlation of the density with strength and stiffness can be observed.

The constants $\mathrm{C}_{1}, \mathrm{C}_{2}, \mathrm{C}_{3}$ and $\mathrm{C}_{4}$ were determined through a non-linear regression analysis with the precondition that the slope of the regression line of the values of $\sin ^{2}(\alpha)$ calculated with Eqs. (5) and (6) should be 1. The correlation graph is shown in Fig. 6. The values of the constants were $\mathrm{C}_{1}=0.12, \mathrm{C}_{2}=25.9, \mathrm{C}_{3}=27.8$ and $\mathrm{C}_{4}=15.0$. These values
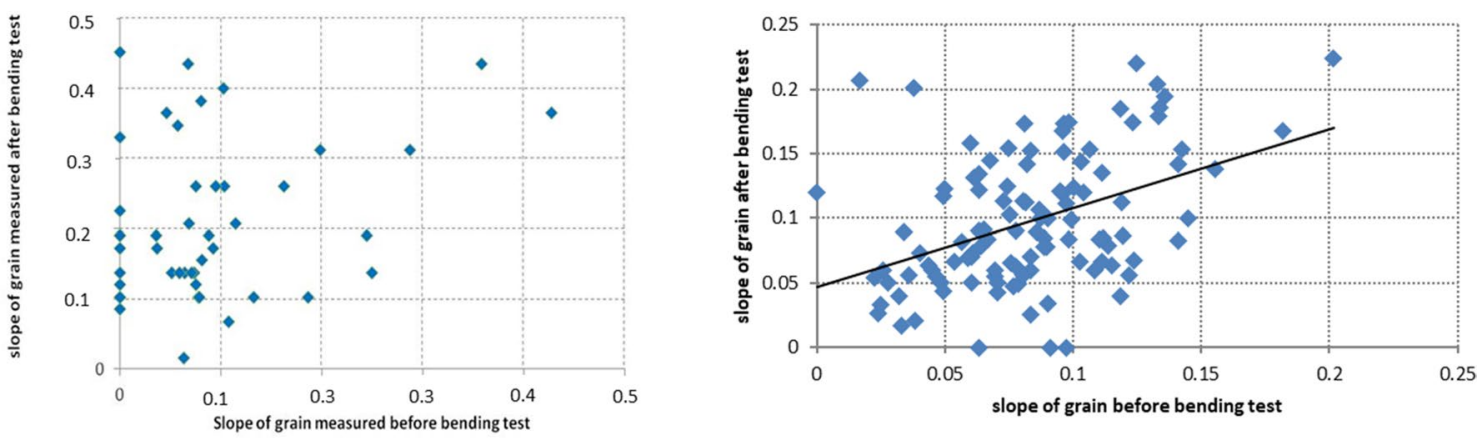

Fig. 4 Slope of grain measured before and after testing for a sample of okan (left) and a sample of greenheart (right) 

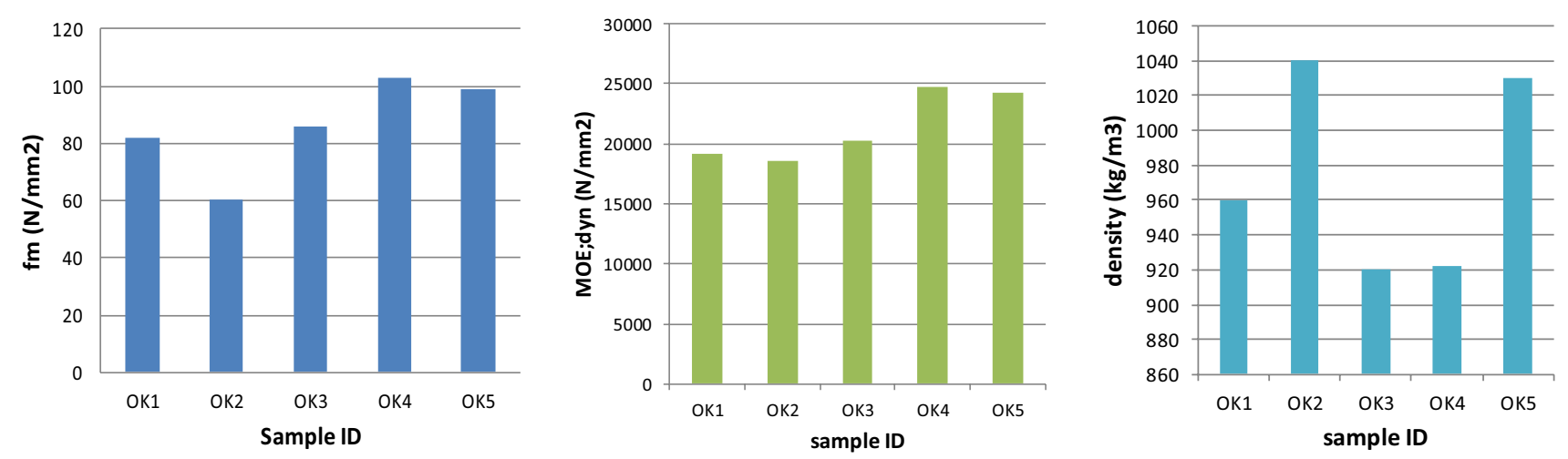

Fig. 5 Mean values of the bending strength (left), dynamic modulus of elasticity (middle) and density (right) at $12 \%$ moisture content for the five okan samples

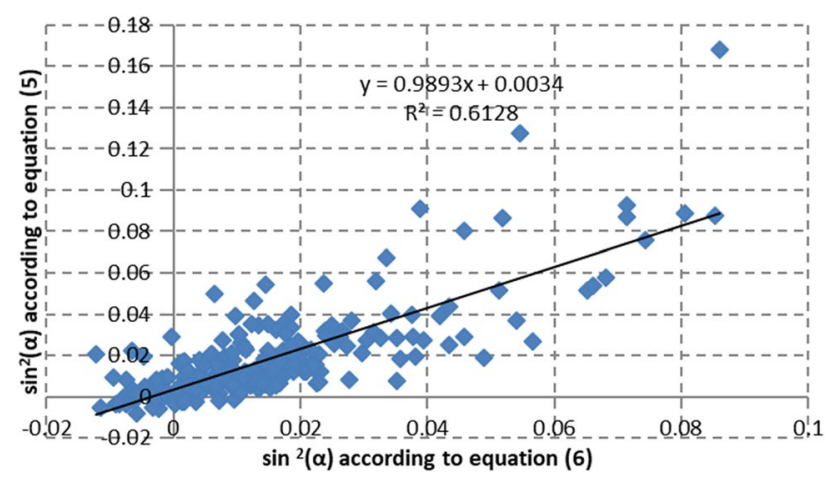

Fig. 6 Relationship between $\sin ^{2}(\alpha)$ calculated with Eqs. (5) and (6)

are consistent with the values found for a dataset of massaranduba according to Ravenshorst and Van de Kuilen (2015). From the calculated values of $\sin ^{2}(\alpha)$, the square root is taken to calculate $\sin (\alpha)$. For negative values of $\sin ^{2}(\alpha)$, the value of $\sin (\alpha)$ is taken as 0 . For every piece, the value of $\sin (\alpha)$ was derived from Eqs. (5) and (6). The average of these two values was taken and from this value, the average angle $\alpha$ was calculated. Finally, the tangent of this average angle $\alpha$ was taken, and this value was designated as the theoretical slope of grain.

\section{Analysis}

Figure 7 shows the slope of grain measured after the bending test, and Fig. 8 shows the theoretical slope of grain, determined according to Sect. 4 . In both figures, the results are compared with the theoretical Hankinson equations according to Eqs. (3) and (4) with the average density of all five samples of okan as input value, and the $\mathrm{C}$-factors as determined in Sect. 4

Figures 7 and 8 show that the theoretically determined slope of grain follows the theoretical Hankinson lines much better for both bending strength and MOE than the slope of grain measured after the test. There are two explanations
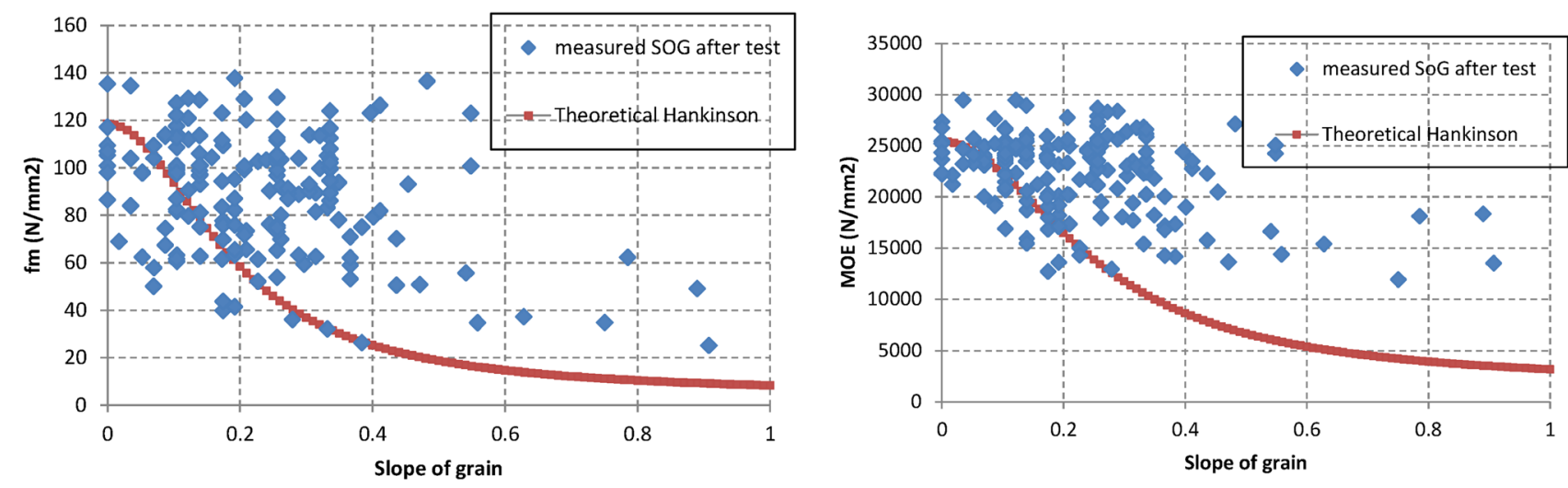

Fig. 7 Bending strength (left) and MOE (right) against the slope of grain measured after testing for the 5 samples of okan and the theoretical Hankinson line 

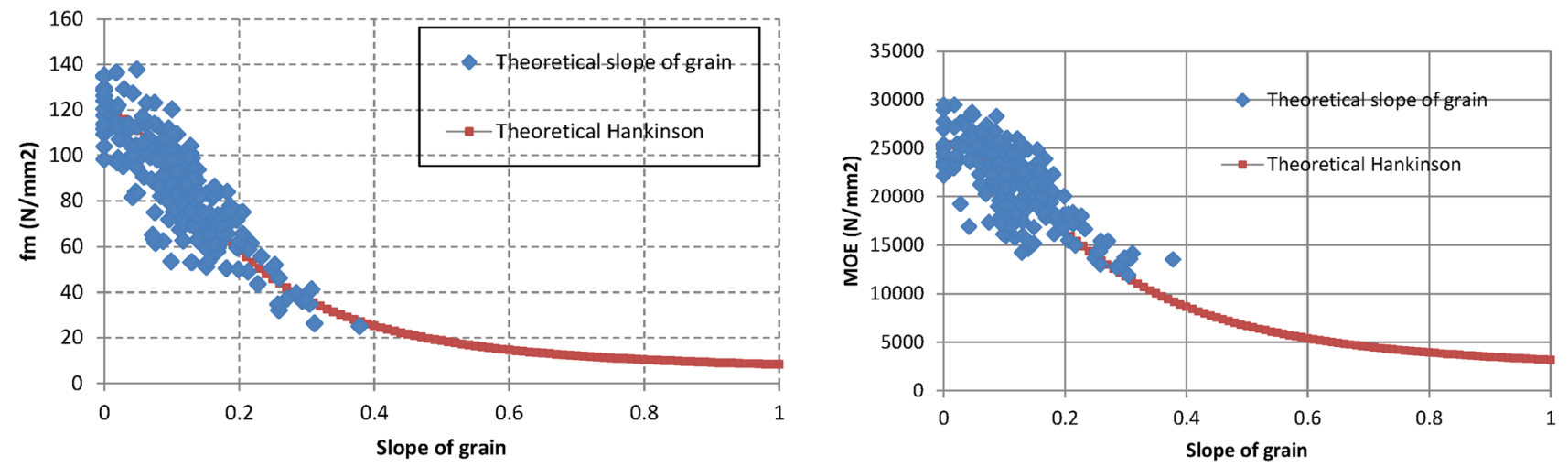

Fig. 8 Bending strength (left) and MOE (right) against the theoretical slope of grain for 5 samples of okan and the theoretical Hankinson line
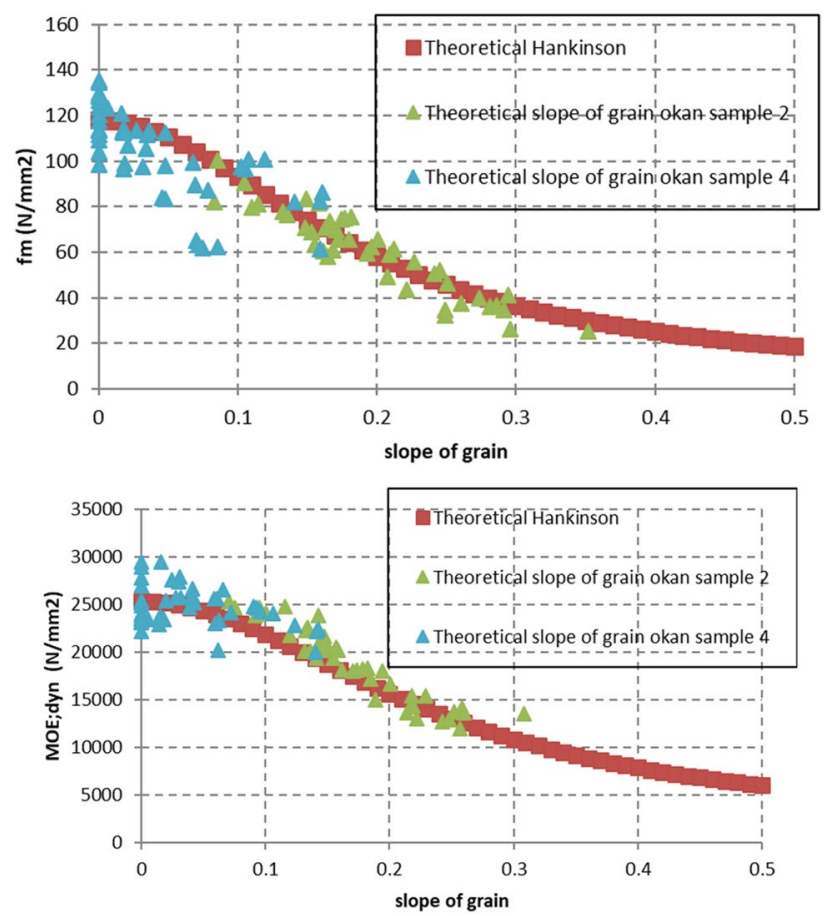

Fig. 9 Bending strength against theoretical slope of grain and theoretical Hankinson line for okan samples 2 and 4 (left) and $\mathrm{MOE}_{\mathrm{dyn}}$ against theoretical slope of grain for okan samples 2 and 4 (right)

for this observation. Firstly, after the bending test, the slope of grain is not always very clear to measure. Secondly, it is difficult to capture the $3 \mathrm{D}$ effect that is present in timber beams. These two effects are more present in the test results of full-size specimens compared to the specifically prepared specimens described in Sect. 2. Figure 9 shows that the theoretical slope of grain values can capture the $3 \mathrm{D}$ effect for bending strength and MOE.

The theoretical slope of grain can be used to investigate the influence of different samples on the overall classification of the species. Figure 8 shows that for pieces that pass the normal grading procedure for visual grading, a

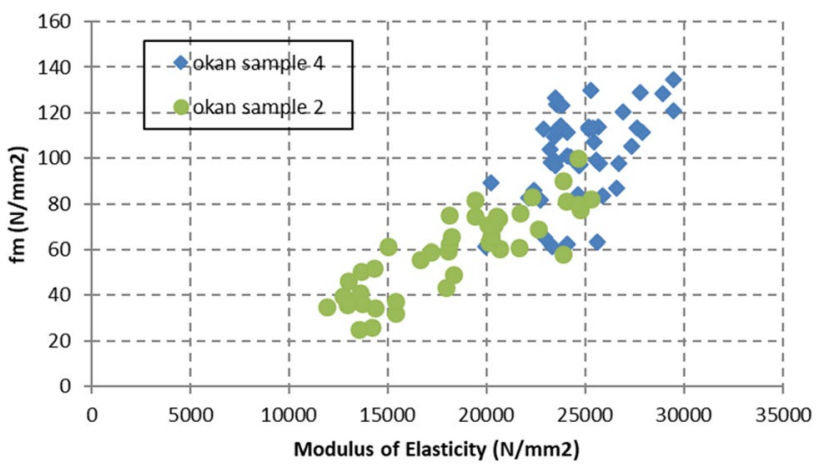

Fig. 10 Bending strength against $\mathrm{MOE}_{\mathrm{dyn}}$ for okan samples 2 and 4 (right)

theoretical slope of grain up to 0.3 occurs. Figure 9 shows the bending strength (left) and the $\mathrm{MOE}_{\text {dyn }}$ (right) against the theoretical slope of grain values for okan samples 2 and 4. Figure 10 shows the bending strength against the $\mathrm{MOE}_{\mathrm{dyn}}$ for okan samples 2 and 4 . Using sample 4 in the testing program and basing the strength class classification on this sample would have the following consequence for the safety of the graded material in practice: the specimens of sample 2 would also pass the visual grading practice (as was shown in Sect. 3.3), but because the actual slope of grain values of sample 2 are much higher than for sample 4 , the strength class assignment of pieces of sample 2 would be unsafe.

Therefore, when the presence of samples with higher slope of grain values cannot be ruled out, for strength class assignments the range of slope of grain values present in the test sample should be more than the threshold value of 0.1 ; a range between 0 and 0.3 seems reasonable. To be sure that these pieces are incorporated, the (dynamic) MOE of pieces can be determined and based on these values, a selection can be made. The MOE for straight grained pieces ( $\mathrm{SoG}$ of 0) according to Ravenshorst and Van de Kuilen (2018) is expected to be the density (for the okan samples an average value of $\left.980 \mathrm{~kg} / \mathrm{m}^{3}\right)$ multiplied by constant $\mathrm{C}_{2}(=25.9)$, 
which gives a value of around 25,400 N/mm². Therefore, sample 4 can be regarded as high quality. For a slope of grain of 0.3 , a value of $11,000 \mathrm{~N} / \mathrm{mm}^{2}$ can be expected.

\section{Conclusion}

For tropical hardwoods, the slope of grain is the most important parameter that influences the bending strength and the modulus of elasticity. The relation of the slope of grain with these parameters can be described with Hankinson equations. Because the slope of grain is more difficult to assess than the size of knots for softwoods, only one visual grade is possible for tropical hardwoods. In practice, it is assessed whether the beams comply with the required limit of 1:10 for the slope of grain or not. The actual value of the slope of grain is not measured. However, it is shown that slope of grain values measured after testing can be much higher than the limit of 1:10, but these values do not follow the Hankinson relations very well. This can be explained by the $3 \mathrm{D}$ effect that is difficult to capture visually.

The theoretical slope of grain can be determined with measurements of the bending strength, the MOE and the density. The theoretical slope of grain follows the Hankinson relations very well. For five samples of okan species, values for the theoretical slope of grain were found ranging from 0 to 0.3 for pieces that pass the normal visual grading assessment.

It is therefore advised that in the testing program for the strength class assignments, specimens with values for the slope of grain up to 0.3 are incorporated in the testing program, when it cannot be ruled out that these pieces might enter the market. The selection of the specimens can be made by calculating the expected dynamic MOE for the range of slope of grain and verify whether specimens with these dynamic MOE values are incorporated. The slope of grain should be measured after testing and the theoretical slope of grain can be calculated. These distributions should be incorporated into the strength class assignment reports. For historical data where no slope of grain data is available, the theoretical slope of grain can be calculated from the density, bending strength and MOE, to evaluate whether the sampling was representative and not only consisted of unique high-quality samples.

Open Access This article is licensed under a Creative Commons Attribution 4.0 International License, which permits use, sharing, adaptation, distribution and reproduction in any medium or format, as long as you give appropriate credit to the original author(s) and the source, provide a link to the Creative Commons licence, and indicate if changes were made. The images or other third party material in this article are included in the article's Creative Commons licence, unless indicated otherwise in a credit line to the material. If material is not included in the article's Creative Commons licence and your intended use is not permitted by statutory regulation or exceeds the permitted use, you will need to obtain permission directly from the copyright holder. To view a copy of this licence, visit http://creativecommons.org/licenses/by/4.0/.

\section{References}

Cibecchini D, Cavalli A, Goli G, Togni M (2016) Beech sawn timber for structural use: a case study for mechanical characterization and optimization of the Italian visual strength grading rule. J For Sci 62:521-528. https://doi.org/10.17221/93/2016-JFS

Ehrhart T, Steiger R, Frangi A (2018) A non-contact method for the determination of fibre direction of European beech wood (Fagus sylvatica L.). Eur J Wood Prod 76:925-935

EN 384 (2016) Structural timber-determination of characteristic values of mechanical properties and density. CEN, Brussels

EN 408 + A1 (2012) Timber structures-structural timber and glued laminated timber-determination of some physical and mechanical properties. CEN, Brussels

EN 1912 (2012) Structural timber—strength classes—assignment of visual grades and species. CEN, Brussels

EN 1310 (2012) Structural timber—strength classes—assignment of visual grades and species. CEN, Brussels

EN 14081-1 (2016) Timber structures-strength graded structural timber with rectangular cross section-Part 1-1. General requirements. CEN, Brussels

EN 16737 (2016) Structural timber. Visual strength grading of tropical hardwood. CEN, Brussels

Hankinson RL (1921) Investigation of crushing strength of spruce at varying angles of grain. U.S. Air Service, Inform. Cir. 3 no. 259

NEN 5493 (2010) Quality requirements for hardwoods in civil engineering works and other structural applications. NEN, Delft

NEN-EN 1995-1-1 (2005) Eurocode 5. Design of timber structuresPart 1-1: General—common rules and rules for buildings. NEN, Delft

Pope DJ, Marcroft JP, Whale LRJ (2005) The effect of global slope of grain on the bending strength of scaffold boards. Holz Roh Werkst 63:321-326

Ravenshorst GJP (2015) Species independent strength grading of structural timber. PhD thesis, Delft University of Technology

Ravenshorst GJP, Van de Kuilen JWG (2016) Species independent strength modeling of structural timber for machine grading. WCTE 2016, Vienna

Ravenshorst GJP, Van de Kuilen JWG (2018) Relationships between non-destructive measurements and mechanical properties of tropical hardwoods. WCTE 2018, Seoul

Publisher's Note Springer Nature remains neutral with regard to jurisdictional claims in published maps and institutional affiliations. 